\title{
Sistem Informasi Pengelolaan Lahan Kawasan Hutan Berbasis Web
}

\author{
Alvian Pahlevi \\ Teknik Informatika Universitas PGRI Madiun Indonesia \\ Email: alvian.pahlevi@myself.com
}

\begin{abstract}
ABSTRAK
Pengelolaan lahan kawasan hutan adalah suatu perhatian terhadap nilai-nilai budaya masyarakat, aspirasi, dan keterlibatan masyarakat kawasan hutan setempat dalam mengelola lahan hutan dengan adanya PHBM (Pengelolaan Hutan berbasis Masyarakat). Dalam upaya untuk memberikan kemudahan untuk melakukan pendataan dimana pada saat ini pengeelolaan data pesanggem lahan hutan di Perum Perhutani KPH Saradan khususnya di bagian PHBM masih dilakukan secara manual dengan cara menulis pada buku besar. Dengan tujuan agar Perum Perhutani KPH Saradan, khususnya bagian PHBM sudah bisa memanfaatkan teknologi aplikasi berbasis web untuk dapat melakukan pendataan yang lebih efisien dari segi waktu maupun biaya serta cetak laporan. Metodologi dari pembuatan skripsi ini menggunakan metodologi Waterfall yang terdiri dari analisis kebutuhan, desain sistem, penulisan kode program, pengujian sistem, serta penerapan dan pemeliharaan aplikasi. Bahasa pemrograman yang digunakan yaitu PHP dengan database menggunakan MySQL. Penelitian ini memberikan hasil sistem informasi pengelolaan lahan kawasan hutan berbasis web yang dapat mempermudah dan membantu dalam pencatatan dan laporan data pesanggem yang dilakukan oleh staff ahli PHBM di Perum Perhutani KPH Saradan, Madiun.
\end{abstract}

Kata Kunci: Pesanggem, Pengelolaan Hutan berbasis Masyarakat (PHBM)

\section{PENDAHULUAN}

Perkembangan teknologi yang semakin maju saat ini sangatlah mempengaruhi segala aspek dalam kehidupan manusia untuk mempermudah pekerjaan ataupun dalam memperoleh sebuah informasi. Informasi diolah dengan baik untuk memperoleh sebuah data yang akurat dan tepat yang kemudian dapat memberikan kemudahan akses data apapun kepada pengguna, salah satunya dalam pengolahan data pada suatu perusahaan dan instansi untuk menunjang sebuah pekerjaan.

Perum Perhutani adalah Badan Usaha Milik Negara (BUMN) yang bergerak dibidang manajemen kehutanan, pemanfaatan dan konservasi hutan alam yang memiliki sistem Pengelolaan Sumber Daya Hutan Kolaboratif. Perusahaan tidak hanya bekerja untuk keuntungan pemilik modal, tetapi juga diperlukan untuk berkontribusi bagi kesejahteraan masyarakat melalui Lembaga Masyarakat Desa Hutan (LMDH).

Pesanggem merupakan sebutan untuk petani yang menggarap lahan hutan milik Perhutani. Petani pesanggem umumnya berasal dari desa sekitar hutan. Mereka mengelola lahan di kawasan hutan yang telah selesai dilaksanakan tebangan oleh Perhutani, dengan ditanami aneka jenis palawija, jagung, porang dan aneka tanaman lainnya.

Sistem pengolahan data para pesanggem dalam pengelolaan lahan kawasan hutan yang berjalan saat ini di Perum Perhutani KPH Saradan masih dilakukan dengan penulisan secara manual data-data para pesanggem pada buku besar arsip per-tahun yang kemudian data tersebut akan dikirimkan ke kantor pusat perhutani sebagai bukti laporan data para pesanggem.

Dengan menganalisis permasalahan tersebut penulis mempunyai gagasan untuk dapat turut serta menyelesaikan permasalahan tersebut dengan membuat sebuah sistem informasi yang dapat membantu untuk mengolah data para pesanggem dalam pengelolaan lahan kawasan hutan. Sistem yang baru ini diharapkan dapat menggantikan sisten yang lama, sehingga 
dapat mengurangi tingkat kesalahan dan kesulitan pada proses pendataan.

Halim Budi Santoso, Dkk (2016) yang berjudul "Pengembangan Sistem Informasi Pendataan Petani Dan Kelompok Tani". Hasil dari penelitian tersebut adalah sebuah pengembangan sistem informasi dengan tujuan untuk mempermudah melakukan proses pendataan para petani dan kelompok tani yang dimana sistem informasi tersebut dikembangkan dengan tampilan web yang lebih efisien dan mudah dimengerti. Pada penelitian skripsi ini memiliki kesamaan dengan penelitian diatas yaitu teknik pengembangan yang sama-sama bertujuan untuk mempermudah dalam pendataan serta membuat laporan dari seluruh data yang ada.

Haris Kristiawan (2014) dengan judul "Analisis dan Perancangan Sistem Informasi Pengelolaan Data Kelompok Tani Pada UPTD DINTANBUNNAKIKAN Kecamatan Jiken". Hasil dari penelitian tersebut adalah untuk mempermudah dalam mengelola data kelompok tani dan melakukan pembukuan dengan cara komputerisasi pada UPTD (Unit Pelaksana Teknis Daerah) DINTANBUNNAKIKAN (Dinas Pertanian Perkebunan Peternakan Perikanan) Jiken serta dapat meningkatkan kinerja dengan mengurangi penggunaan kertas, bolpoint, dan buku. Karena dengan sistem komputerisasi proses pelayanan kelompok tani lebih cepat dan tidak berfokus lagi pada penyimpanan saat menggunakan buku. Pada penelitian skripsi ini memiliki kesamaan dengan penelitian diatas yang dimana perdataan syang sebelumnya dilakuan secara manual dengan pembukuan media kertas diharapkan dapat lebih efisien jika proses tersebut dilakukan secara komputerisasi.

\section{KAJIAN TEORI Sistem}

Menurut Muslihudin (2016), "Sistem adalah suatu grup dari elemenelemen baik berbentuk fisik maupun bukan fisik yang menunjukkan suatu kumpulan saling berhubungan diantaranya dan berinteraksi bersamasama menuju satu ayau lebih tujuan, sasaran atau akhir dari sistem". Menurut Irwansyah (2014), "Sistem adalah sekumpulan elemen yang saling terkait atau terpadu yang dimaksudkan untuk mencapai suatu tujuan".

Informasi

Informasi adalah hasil pemrosesan data (fakta) menjadi sesuatu yang bermakna dan bernilai untuk pengambilan keputusan. Informasi adalah data yang diolah menjadi bentuk yang berguna bagi para pemakainya (F. Wongso, 2015)

\section{Lahan}

Menurut FAO dalam Novita dan N. Sari (2015), "lahan mempunyai pengertian yang hampir serupa dengan sebelumnya bahwa lahan adalah bagian dari bentang alam yang mencakup pengertian fisik termasuk iklim, topografi/relief, hidrologi, bahkan keadaan vegetasi yang secara potensial akan berpengaruh terhadap penggunaan lahan".

\section{Website}

Menurut Irwansyah dan J. V. Moniaga (2014), "Website adalah keseluruhan halaman-halaman web yang terdapat dari sebuah domain yang mengandung informasi". Menurut Irwansyah dan Moniaga, "Website merupakan salah satu layanan yang didapat oleh pemakai komputer yang terhubung ke internet".

\section{METODE PENELITIAN}

Pada penelitian ini model waterfall digunakan sebagai pendekatan atau model penelitian dalam pembuatan sistem informasi pengelolaan lahan. Yaitu sebagai berikut : 


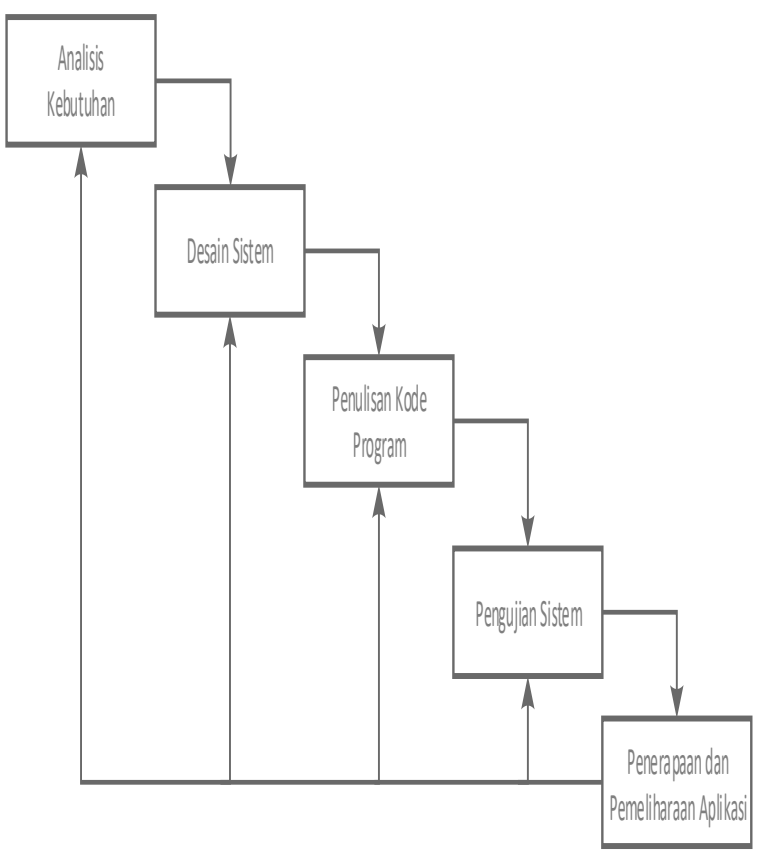

Gambar 2. Metode Waterfall

Keterangan :

1. Analisis Kebutuhan

Tahapan proses pencarian kebutuhan data yang akan dikumpulkan untuk pembuatan sistem.

2. Desain Sistem

Tahapan ini dilakukan dengan mengolah data yang didapat dari tahap pertama dalam bentuk racang perangkat lunak yang akan dibuat berupa diagram, flowchart, arsitektur perangkat lunak, dan tampilan program.

3. Penuliasan Kode Program

Proses mengubah bentuk dari desain sistem kedalam bahasa pemrograman agar dapat sibaca oleh komputer melewati proses coding oleh pemrogram.

4. Pengujian Sistem

Tahap uji coba pada aplikasi yang telah dibuat untuk mengetahui adanya kesalahan dalam sistem.

5. Penerapan dan Pemeliharaan Aplikasi Pada tahap ini dilakukan penerapan dan pemeliharaan pada aplikasi yang sudah dibuat dan berhasil pada tahap uji coba agar aplikasi dapat terus berfungsi dengan baik.
Untuk menghasilkan sebuah penelitian dengan data dari hasil yang tepat, maka dibutuhkan tempat yang memiliki kesesuaian dengan rancangan aplikasi yang di bangun. Adapun tempat yang sesuai di jadikan obyek penelitian di Perum Perhutani KPH Saradan, Madiun dengan metode pengembangan sistem Waterfal. Penelitian ini membutuhkan waktu 4 bulan yaitu dimulai dari tanggal 1 April 2018 sampai dengan 31 Juli 2018.

\section{HASIL DAN PEMBAHASAN}

Rancangan proses sistem menggunakan perancangan model UML (Unified Modeling Language) yang terdiri dari use case diagram, activity diagram dan class diagram.

\section{Use Case Diagram}

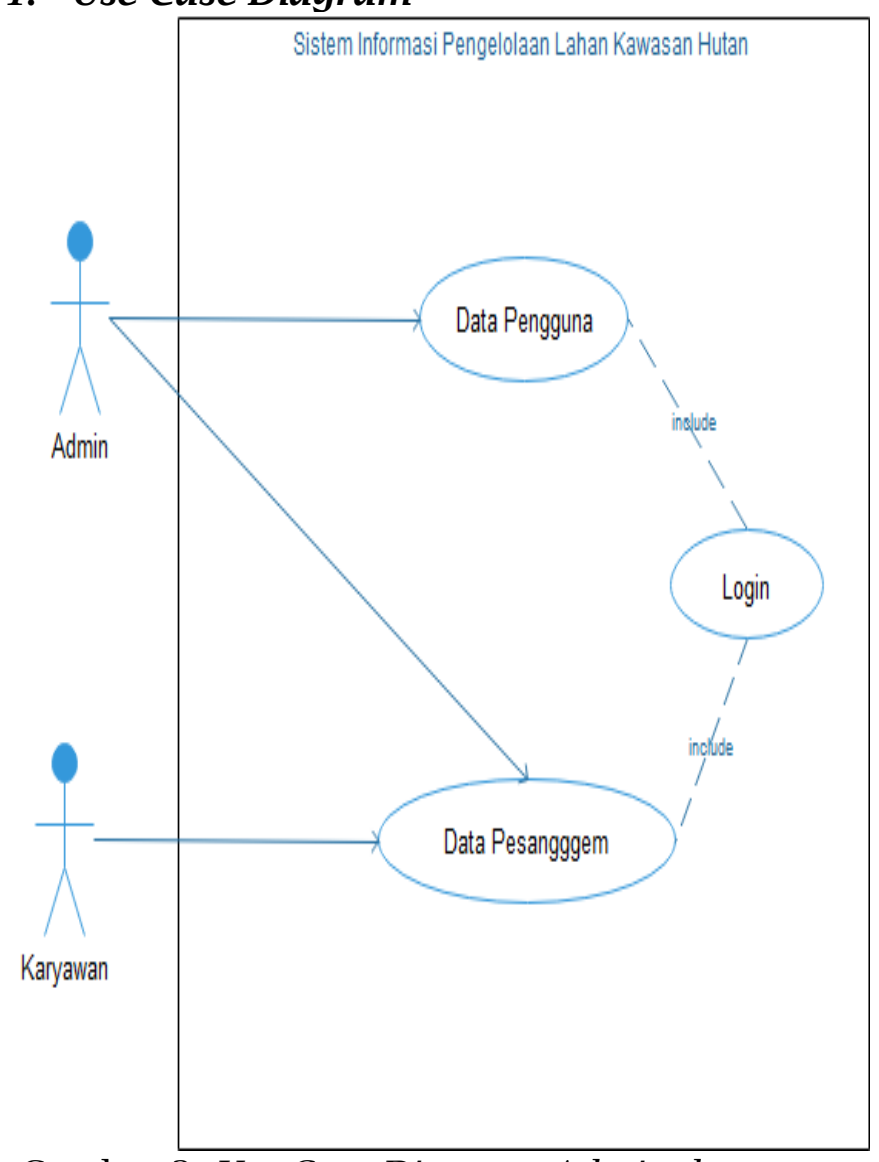

Gambar 3. Use Case Diagram Admin dan Karyawan

\section{Class Diagram}




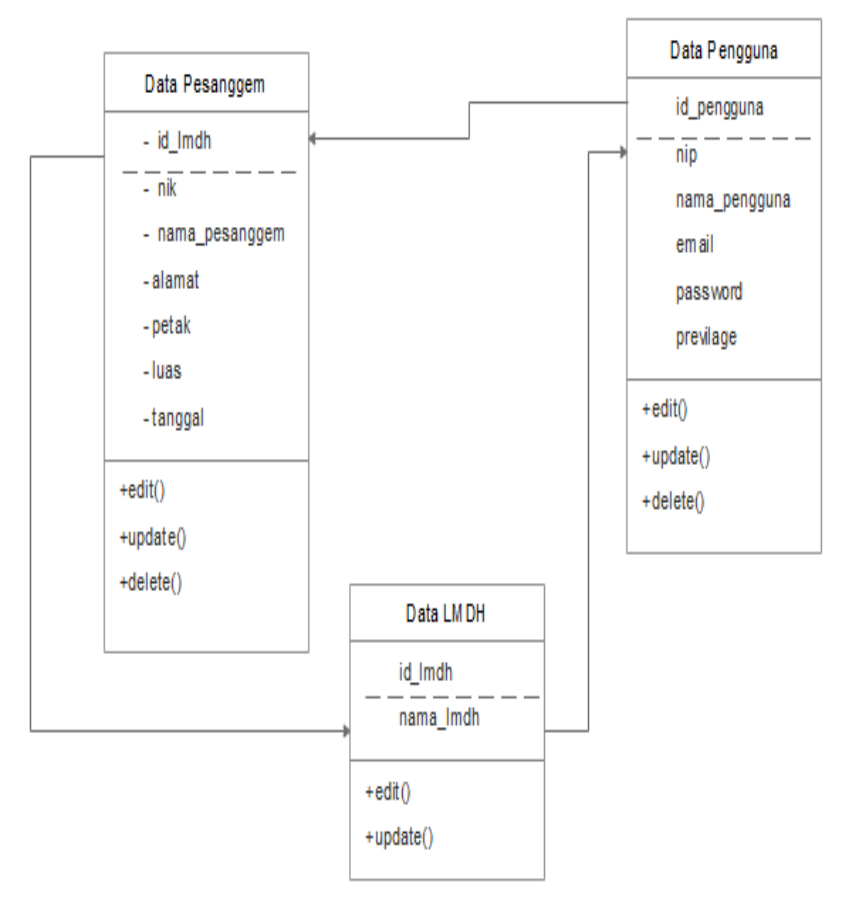

Gambar 4. Class Diagram

\section{Activity Diagram}

Activity Diagram Pencatatan Data Pesanggem

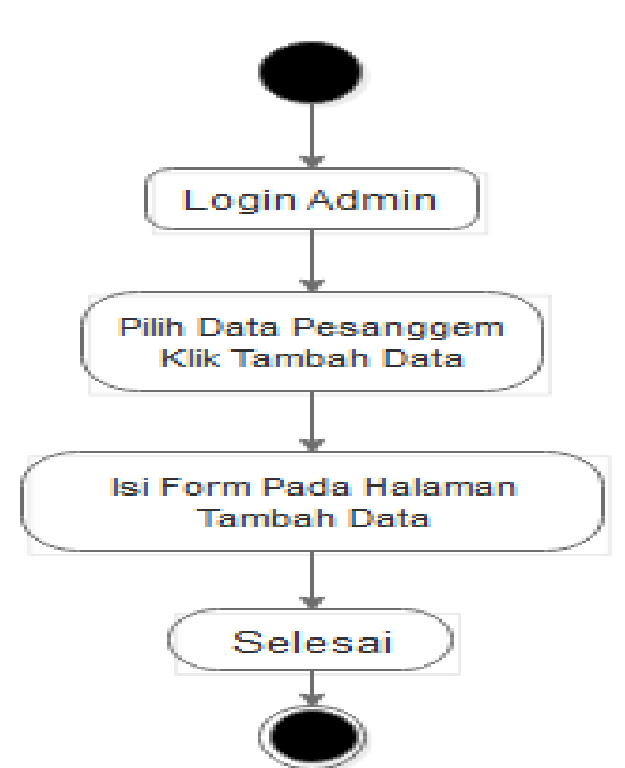

Gambar 5. Activity Diagram Pencatatan Data

\section{IMPLEMENTASI}

Aplikasi sistem informasi pengelolaaan lahan kawasan hutan memiliki tampilan antar muka dan proses pengolahan data-data yang telah diimplementasikan pada gambar dan penjelasan berikut :

\section{Tampilan Administrator}

Tampilan Login

Tampilan ini adalah tampilan yang digunakan oleh user atau admin yang sebelumnya harus melakukan login terlebih dahulu 


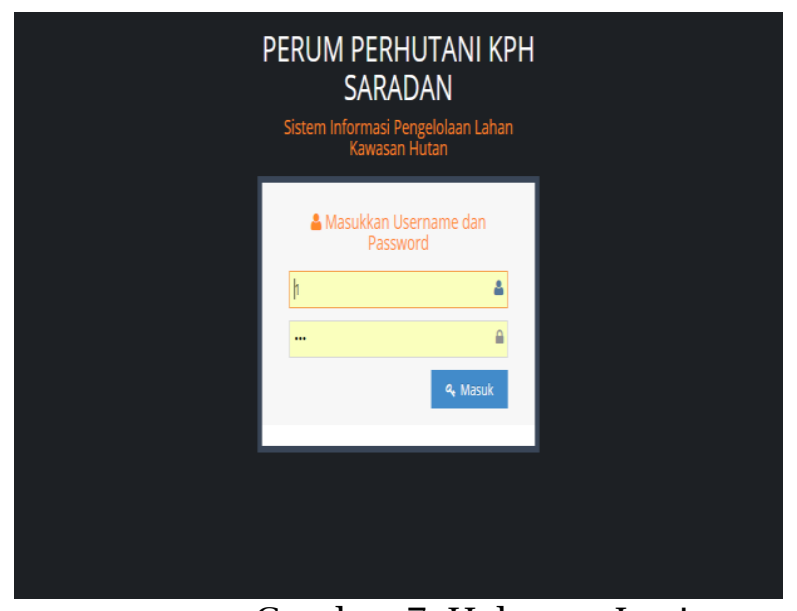

Gambar 7. Halaman Login

Tampilan Halaman Tambah Data

Pada tampilan halaman ini admin dapat melakukan tambah data pesanggem dengan mengisikan pada form yang tersedia.

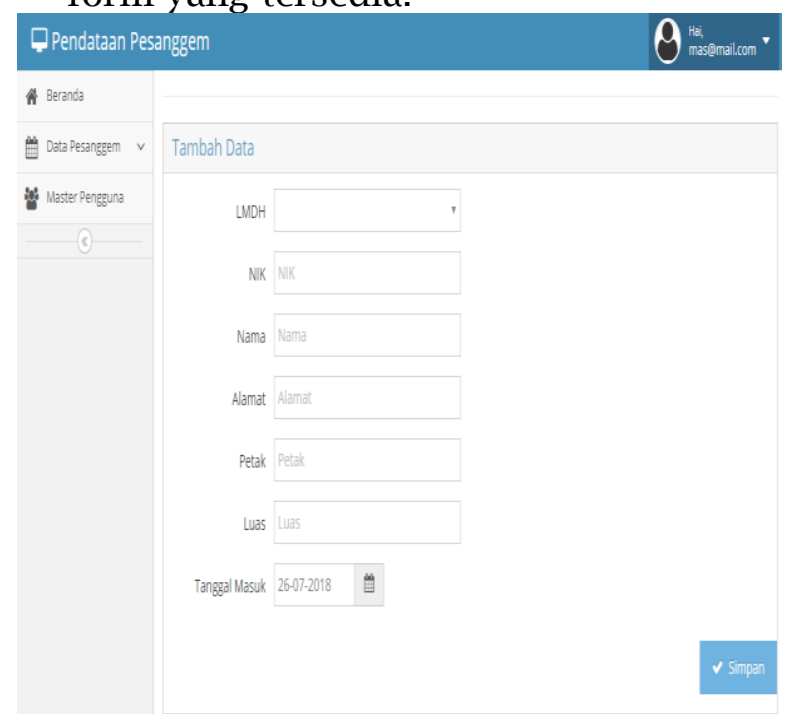

Gambar 8. Halaman Tambah Data

\section{Tampilan Karyawan}

a. Tampilan Karyawan

Pada halaman ini karyawan dapat melihat, mencari, dan mencetak data pesanggem.

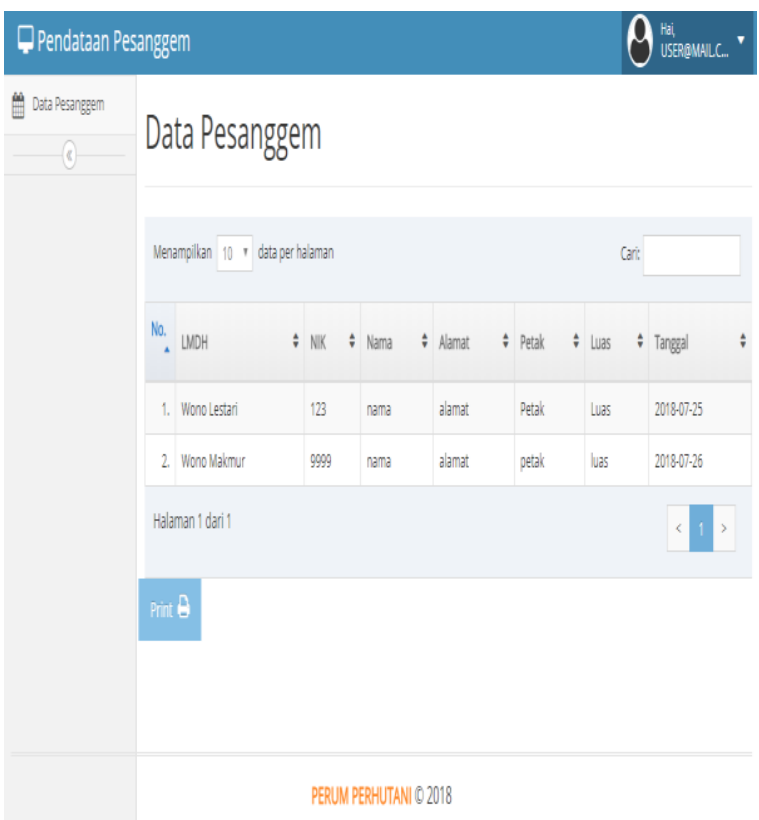

Gambar 9. Halaman Pesangem

\section{KESIMPULAN}

Berdasarkan hasil penelitian dan pembahasan dari penelitian saat ini adalah sistem informasi pengelolaan lahan kawasan hutan yang dibangun cukup mempermudah staff PHBM dalam mencatat dan mengelola data pesanggem, serta mempermudah dalam melakukan cetak laporan dari data pesanggem. Dengan aplikasi ini pencatatan data pesanggem terlihat lebih mengikuti perkembangan teknologi dan modern

\section{DAFTAR PUSTAKA}

F. Wongso. 2015. "Perancangan Sistem Informasi Penjualan Berbasis Java Studi Kasus Pada Toko Karya Gemilang Pekanbaru," Jurnal Ilmiah Ekonomi Dan Bisnis, vol. 12, no. 1, p. 48.

Halim . B. Santoso, C. Malvin dan R. Delima. 2017. "Pengembangan Sistem Informasi Pendataan Petani dan Kelompok Tani," Seminar Nasional Sistem Informasi, pp. 5968.

Haris, Kristiawan. 2013. "Analisis dan Perancangan Sistem Informasi Pengolahan Data Kelompok Tani Pada UPTD DINTANBUNNAKIKKAN Kecamatan Jiken,” pp. 1-9. 
Irwansyah dan J. V. Moniaga. 2014. "Pengantar Teknologi Informasi," Yogyakarya, Deepublish, p. 34.

Muslihudin dan O. 2016. , "Analisis dan Perancangan Sistem Informasi Menggunakan Model Terstruktur dan UML," Yogyakarta, CV ANDI OFFSET, p. 9.

Novita dan N. Sari. 2015. "Sistem Informasi Peenjualan Pupuk Berbasis E-Commerce," TEKNOIF, vol. 3, no. 2, p. 2. 